\title{
Sistem Fonem Isolek Kuntu Kabupaten Kampar
}

\section{Phoneme System Of Kuntu Isolect Kampar Regency}

Atri Kehana Masni*, Nadra Nadra \& Rina Marnita AS

Program Studi Linguistik, Fakultas Ilmu Budaya, Universitas Andalas, Indonesia

Pos-el: atrikehanamasni@gmail.com

Kajian sinkronis ini mendeskripsikan sistem fonem isolek Kuntu, salah satu isolek yang digunakan di Kabupaten Kampar, Provinsi Riau. Data merupakan tuturan informan menggunakan isolek Kuntu terkait kosakata yang telah disiapkan. Pengumpulan data dilakukan dengan cara merekam dan mewawancarai informan terpilih, menggunakan metode simak dan metode cakap, dan dianalisis menggunakan metode padan dan premis dasar Pike (1966). Berdasarkan hasil analisis, IKKK memiliki 42 bunyi, yaitu bunyi vokoid, kontoid, dan diftong. Sistem fonem IKKK memiliki 33 fonem yang terdiri atas, lima fonem vokal, delapan belas fonem konsonan, dan sepuluh fonem diftong. Suku kata isolek Kuntu terdiri atas delapan pola, yaitu V, VK, KV, KD, KVK, KKV, KDK, dan KKVK. Keberagaman fonem diftong isolek Kuntu yang ditemukan pada penelitian ini tidak jauh berbeda dengan penelitian sebelumnya. Hal ini membuktikan bahwa isolek Kuntu Kabupaten Kampar merupakan dialek bahasa Minangkabau meski Desa Kuntu secara administrasi pemerintahan berada di wilayah Provinsi Riau. Disamping itu, sistem adat yang digunakan oleh masyarakat Desa Kuntu (matrilineal) menjadi bukti lain bahwasannya Desa Kuntu Kabupaten Kampar memiliki hubungan dengan Minangkabau.

Kata kunci: Fonologi; Sistem Fonem; Isolek Kuntu

\section{Abstract}

This synchronic study describes the phoneme system of the Kuntu isolect, one of the isolects used in Kampar Regency, Riau Province. The data is the informant's speech using the Kuntu isolect related to the prepared vocabulary. Data was collected by recording and interviewing selected informants, using the listening and speaking method, and analyzed using the equivalent method and the basic premise of Pike (1966). Based on the results of the analysis, IKKK has 42 sounds, namely vocoid, contoid, and diphthong sounds. The IKKK phoneme system has 33 phonemes consisting of five vowel phonemes, eighteen consonant phonemes, and ten diphthong phonemes. Kuntu isolect syllables consist of eight patterns, namely $V, V K, K V, K D, K V K, K K V, K D K$, and $K K V K$. The diversity of Kuntu isolect diphthong phonemes found in this study is not much different from previous studies. This proves that the Kuntu isolect of Kampar Regency is a Minangkabau dialect even though Kuntu Village is administratively located in the Riau Province. In addition, the customary system used by the people of Kuntu Village (matrilineal) is another proof that Kuntu Village, Kampar Regency has a relationship with Minangkabau.

Keywords: Phonology; Phoneme System; Kuntu Isolect 


\section{PENDAHULUAN}

Desa Kuntu merupakan salah satu desa yang terletak di Kecamatan Kampar Kiri, Kabupaten Kampar, Provinsi Riau dan termasuk daerah daratan, yang bersebelahan dengan Sungai Subayang. Secara geografis, Desa Kuntu terletak di sebelah utara Desa Tanjung Emas, sebelah selatan Desa Kuntu Darussalam, sebelah Timur Desa Teluk Paman, dan sebelah Barat Desa Padang Sawah.

Sebelum diterbitkannya UndangUndang RI Nomor 61 pada tahun 1958 terkait pembentukan daerah-daerah swatantra, Riau, Sumatera Barat, dan Jambi merupakan satu wilayah Provinsi Sumatera Tengah. Selain itu, dalam buku Sejarah Minangkabau yang terbit tahun 1970-an, dikatakan bahwa Kuntu termasuk wilayah Minangkabau Timur yaitu Kerajaan Kuntu Timur (Arman, 2014).

Sistem adat yang digunakan oleh masyarakat Desa Kuntu juga berasal dari adat Minangkabau yaitu menganut sistem garis keturunan menurut ibu (matrilineal). Sumarsono dkk. (1997) juga menyebutkan bahwa syarat bagi seorang penghulu dalam suatu kampung di Kampar Kiri Kabupaten Kampar ialah turunan satu rumah menurut garis ibu (matrilineal).

Hamidy (1994) mengatakan bahwa bahasa yang digunakan oleh masyarakat Provinsi Riau adalah bahasa Melayu Riau yang terbagi atas enam dialek, salah satunya dialek Melayu Kampar. Namun, dalam penelitian Nadra (2003) menemukan dialek bahasa Minangkabau di Provinsi Riau, termasuk pada Desa Kuntu Kabupaten Kampar. Berdasarkan pendapat Hamidy (1994) dan penelitian Nadra (2003), objek penelitian ini selanjutnya disebut sebagai isolek Kuntu Kabupaten Kampar atau disingkat menjadi IKKK.
Penelitian bahasa yang telah dilakukan di Kabupaten Kampar, yaitu penelitian oleh Ermawati dan Hermaliza (2019), Faizah AR (2012), dan Martius (2012). Namun, peneltian-penelitian tersebut tidak dilakukan di desa Kuntu dan bukan penelitian yang khusus membahas sistem fonem isolek Kuntu.

Penelitian Nadra (2003) merupakan satu-satunya penelitian yang dilakukan di Desa Kuntu dengan menjadikan Kuntu sebagai salah satu dari 30 titik pengamatannya. Nadra (2003) meneliti dialek bahasa Minangkabau di Provinsi Riau. Penilitian Nadra (2003) menyimpulkan bahwa bahasa Minangkabau yang ditemukan di Provinsi Riau dapat digolongkan atas empat dialek, yaitu dialek Kampar-Indragiri Hulu (Kh), dialek Cerenti-Peranap (Cp), dialek Punti Anai-Kaloyang (Pky), dan dialek Talang Mamak (Tm). IKKK dalam penelitian tersebut termasuk ke dalam dialek Kh.

Penelitian lain yang juga mengkaji sistem fonem dilakukan oleh Krulikowska dkk. (2020). Sistem fonologi bahasa Melayu Jambi isolek Sarolangun oleh Krulikowska dkk. (2020) ditentukan dengan teori Pike (1966). Penelitian Krulikowska dkk. (2020) menemukan 25 fonem dan enam pola suku kata, serta menemukan nasalisasi bunyi vokoid, kehilangan berbagai kontoid maupun seluruh silabel, serta penambahan semivokal.

Sebelumnya, Yuliandari dkk. (2015) mengkaji bahasa Melayu Riau dialek Pematang Selunak Indragiri Hulu. Penelitian Yuliandari dkk. terbatas pada deskripsi fonem segmental bahasa Melayu Riau dialek Pematang Selunak dan hasilnya ditemukan sebanyak 30 fonem segmental yaitu dengan melakukan uji 
pasangan minimal menurut teori Kridalaksana (2001).

Secara spesifik, penelitian ini bertujuan untuk memperoleh deskripsi sistem fonem yang digunakan pada IKKK yang meliputi deskripsi dan klasifikasi (1) bunyi-bunyi dan fonem-fonem; (2) distribusi fonem-fonem; dan (3) deskripsi pola suku kata atau sistem fonotaktik.

\section{LANDASAN TEORI}

Sistem suatu bahasa dapat ditentukan menggunakan fonologi. Fonologi merupakan salah satu cabang ilmu murni linguistik dalam menentukan bunyi-bunyi ujar manusia sehingga menjadi sistem suatu bahasa. Adapun beberapa teori yang digunakan dalam penelitian ini adalah teori (1) deskripsi bunyi, (2) deskripsi fonem, (3) distribusi fonem, dan (4) deskripsi pola suku kata.

Proses diproduksinya suatu bunyi diteliti menggunakan fonetik artikulatoris. Landasan teoritis deskripsi bunyi mengacu pendapat Katamba (1989). Menurut Katamba (dalam Ningsih dan Purwaningsih, 2013:75) fonetik artikulatoris merupakan pendekatan untuk mengetahui bagaimana suatu bunyi diproduksi sehingga dapat menentukan bunyi vokoid, bunyi kontoid, dan diftong. Misal, bunyi nasal diproduksi dengan udara yang dikeluarkan melalui hidung (Katamba, 1989:7).

Selain fonetik, juga dikenal istilah fonemik. Bidang fonemik mengkaji bunyibunyi suatu bahasa sebagai pembeda makna (fonem). Deskripsi fonem dianalisis menggunakan premis-premis dasar fonemik Pike (1966), yaitu melaui uji pasangan minimal dan distribusi komplementer. Menurut Krulikowska dkk. (2020), premis dasar fonemik Pike ini digunakan sebagai metode pelengkap dalam proses analisis.

Pendapat McMahon (2001) digunakan untuk mendeskripsikan distibusi dari fonem-fonem yang ditemukan. Distribusi fonem IKKK dalam kata diklasifikasikan atas tiga posisi, yaitu posisi awal, tengah, dan akhir. Penentuan distribusi fonem dapat membantu peneliti menentukan sistem fonem pada suatu bahasa. Menurut McMahon (2001), melalui penilaian kembali fonem-fonem yang ada pada data, akan terlihat distribusi dari masing-masing fonem.

Landasan teoritis dalam menentukan pola suku kata mengacu pendapat Clements dan Keyser (1983). Clements dan Keyser (dalam Hamid dkk., 2016:8) mengidentifikasi dua unsur pola model suku kata KV-fonologi generative, yaitu V (vokal) dan K (konsonan). Namun karena ditemukan pola suku kata dengan diftong dalam IKKK, maka ditambahkan pola suku kata $\mathrm{D}$ (diftong).

\section{METODE PENELITIAN}

Penelitian lapangan ini menggunakan metode penelitian kualitatif. Data penelitian ini diperoleh dari lima orang informan dan bantuan satu orang pendamping peneliti. Informan dan jumlah informan dipilih berdasarkan syarat-syarat yang dikemukakan oleh Nadra dan Reniwati (2009), yaitu penduduk asli daerah penelitian berusia 40 - 60 tahun dengan alat ucap yang lengkap, yang lahir dan dibesarkan serta menikah dengan orang yang berasal dari daerah penelitian. Lima orang informan dipilih karena keterbatasan waktu penelitian, jumlah informan ditetapkan agar perselisihan jawaban pada pengumpulan data lebih mudah ditangani. 
Data dikumpulkan menggunakan metode simak dan metode cakap (Sudaryanto, 1988) secara bergantian selama proses penelitian. Wawancara dengan narasumber dilakukan menggunakan daftar pertanyaan Nadra dan Reniwati (2009) dan tambahan daftar kosakata pasangan minimal bahasa Indonesia yang telah disiapkan sebelumnya. Korpus berupa catatan selama proses wawancara berlangsung, rekaman dalam bentuk audio dan video, dan transkripsi fonetis. Setelah ditranskripsikan, jumlah data yang diperoleh adalah 668 data.

Fonem-fonem IKKK diidentifikasi menggunakan metode padan (Sudaryanto, 2015) dan premis-premis dasar analisis fonem (Pike, 1966), yaitu premis tiga dan empat tentang uji pasangan minimal dan distribusi komplementer. Selain itu, sistem fonem IKKK juga dapat ditentukan dengan deskripsi distribusi fonem tersebut dalam kata, serta deskripsi pola suku kata yang dimiliki.

\section{PEMBAHASAN}

Berdasarkan hasil analisis, dapat disimpulkan bahwa IKKK memiliki 42 bunyi, yaitu bunyi vokoid, kontoid, dan diftong. Sistem fonem IKKK memiliki 33 fonem yang terdiri atas, lima fonem vokal, delapan belas fonem konsonan, dan sepuluh fonem diftong.

Kelima fonem vokal tersebut ialah fonem /i/ dengan alofon $[\mathrm{i} \sim \mathrm{I}]$, /e/ dengan alofon $[\mathrm{e} \sim \varepsilon], / \mathrm{u} /, / \mathrm{o} /$ dengan alofon $[\mathrm{o} \sim \mathrm{\rho}]$, dan $/ \mathrm{a} /$.

Delapan belas fonem konsonan ini adalah fonem konsonan hambat $/ \mathrm{p} /, \mathrm{b} / \mathrm{b} / \mathrm{t} /$, /d/, /c/, /j/, /k/ dengan alofon [k ?], dan $/ \mathrm{g} /$; fonem konsonan nasal /m/, /n/, /n/, dan /y/; fonem konsonan frikatif/s/, /ь/, dan /h/; fonem konsonan lateral $/ \mathrm{l} /$; dan fonem konsonan semivokal /w/ dan /y/.

Sepuluh diftong tersebut adalah fonem /ie/ dengan alofon [ie i $\varepsilon$ ], /ia/, /iy/, /uo/ dengan alofon [uo uo], /ua/ dengan alofon [ua uə], /uy/, /uw/, /ay/, /aw/, dan low/.

\section{Inventarisasi Bunyi}

Inventarisasi bunyi vokoid, kontoid, dan diftong yang ditemukan dalam IKKK serta contoh datanya dapat dilihat pada tabel berikut.

Tabel 1. Bunyi Kontoid IKKK dan

$$
\text { Contoh Data }
$$

\begin{tabular}{|c|c|c|}
\hline Bunyi & & ntoh Data \\
\hline [p] & [patamo] & 'pertama' \\
\hline [b] & [bawa] & 'bawah' \\
\hline$[\mathrm{t}]$ & [talino] & 'telinga' \\
\hline [d] & [дава] & 'darah' \\
\hline [c] & [coca] & 'sebentar' \\
\hline [j] & [jantuon] & 'jantung' \\
\hline$[\mathrm{k}]$ & [kido] & 'kiri' \\
\hline [g] & [goman] & 'wajah' \\
\hline [?] & {$[\mathrm{d} \varepsilon ?]$} & 'karena' \\
\hline$[\mathrm{m}]$ & [muko] & 'depan' \\
\hline [n] & [ninia?] & 'nenek' \\
\hline [n] & [nalow] & 'menyala' \\
\hline [y] & [nunus] & 'gusi' \\
\hline [s] & [sotu] & 'sabtu' \\
\hline [в] & [воbа?a] & 'rabu' \\
\hline [h] & [ahat] & 'minggu' \\
\hline [1] & [layi] & 'lari' \\
\hline [w] & [awan] & 'awan' \\
\hline [y] & [boyo] & 'buaya' \\
\hline
\end{tabular}


Tabel 2. Bunyi Vokoid IKKK dan Contoh Data.

\begin{tabular}{|c|c|}
\hline Bunyi & Contoh Data \\
\hline [i] & [linta] 'lintah' \\
\hline$[\mathrm{I}]$ & [Ijaw] 'hijau' \\
\hline [e] & 'tarik' \\
\hline$[\varepsilon]$ & [doke?] 'dekat' \\
\hline [a] & [ate] \\
\hline$[\mathrm{u}]$ & [uвє?] 'urat' \\
\hline [o] & 'hidap' \\
\hline [ग] & [Jlan] 'elang' \\
\hline
\end{tabular}

Tabel 3. Bunyi Diftong IKKK dan Contoh Data

\begin{tabular}{|c|c|}
\hline Bunyi & Contoh Data \\
\hline [uo] & [tujus] \\
\hline [uo] & [tunjuo?] 'telunjuk' \\
\hline [ua] & [Isua?] \\
\hline [uə] & [tukuə] \\
\hline [ia] & [koniay] 'kening' \\
\hline [iu] & [taliuw] 'leher' \\
\hline [ie] & [kiyambie] 'kelapa' \\
\hline [ic] & [kasik?] 'pasir' \\
\hline [uy] & 'seratus' \\
\hline [iy] & [maniy] \\
\hline [ay] & [tapay] \\
\hline [عy] & 'gerimis' \\
\hline [uw] & [Ikuw] \\
\hline [aw] & [baliyaw] 'beliau' \\
\hline [ow] & [doyow] 'dengar' \\
\hline
\end{tabular}

Deskripsi fonem IKKK dikategorikan menjadi vokal, konsonan, dan diftong. Fonem dan distibusinya kemudian dirangkum secara singkat dalam tabel sesuai fonem.

\section{Deskripsi dan Distribusi Vokal}

Uji pasangan minimal yang dilakukan menghasilkan lima buah fonem vokal seperti yang ditampilkan pada tabel berikut.
Tabel 4. Pasangan Minimal Vokal IKKK

\begin{tabular}{|c|c|c|}
\hline $\begin{array}{c}\text { Fonem } \\
\text { Vokal }\end{array}$ & $\begin{array}{c}\text { Pasangan } \\
\text { Minimal }\end{array}$ & Makna \\
\hline \multirow{2}{*}{$/ \mathrm{i} / / \mathrm{u} /$} & [ayi] & 'hari' \\
\hline & [ayu] & 'air' \\
\hline \multirow{2}{*}{$/ \mathrm{u} / / \mathrm{a} /$} & [sudu] & 'sendok' \\
\hline & [suda] & 'siap’ \\
\hline \multirow{2}{*}{$/ \mathrm{o} / / \mathrm{u} /$} & [potuy] & 'petir' \\
\hline & [putuy] & 'putus' \\
\hline \multirow{2}{*}{ /a/ /o/ } & [gale] & 'dagangan' \\
\hline & [gole] & 'gelas' \\
\hline \multirow{2}{*}{ /e/ /uy/ } & [sate] & 'satai' \\
\hline & [satuy] & 'seratus' \\
\hline
\end{tabular}

Analisis data juga menunjukkan adanya vokal-vokal yang distribusinya bersifat komplementer yang dapat dilihat pada berikut.

Tabel 5. Distribusi Komplementer Vokal IKKK

\begin{tabular}{|c|c|c|}
\hline Alofon & \multicolumn{2}{|c|}{ Distribusi Komplementer } \\
\hline \multirow{3}{*}[\mathrm{e}]{$[\varepsilon]$} & [elo]'tarik' & [de?]'karena' \\
\hline & [teyo?]'melihat' & [ketع?]'sedikit' \\
\hline & [lipe]'lipas' & [dape?]'dapat' \\
\hline \multirow{3}{*}{ [i] [I] } & [imbo]'hutan' & [Ijaw]'hijau’ \\
\hline & [tibo]'sampai' & [Iduw]'cium' \\
\hline & [layi]'lari' & [Iduy?]'hidup' \\
\hline \multirow{3}{*}{ [o] [०] } & [Ino]'dia' & [onam]'enam' \\
\hline & [golay]'gelang' & [эвау]'mulut' \\
\hline & [loba]'lebah' & [эma?]'ibu' \\
\hline
\end{tabular}

Bunyi $[e]$ dan $[\varepsilon]$ merupakan alofon dari fonem /e/. Bunyi [e] ditemukan pada posisi awal, tengah, dan akhir kata seperti pada [elo] 'tarik', [teno?] 'melihat', dan [lipe] 'lipas', sedangkan bunyi $[\varepsilon]$ hanya ditemukan pada posisi akhir sebelum konsonan seperti pada [de?] 'karena'. Bunyi [e] dan bunyi $[\varepsilon]$ dikatakan berdistribusi komplementer karena kedua bunyi tersebut berada dalam distibusi yang saling melengkapi. 
Bunyi [i] dan [I] merupakan alofon dari fonem vokal /i/. Seperti yang terlihat pada Tabel 5. alofon [i] dari fonem /i/ ditemukan pada posisi awal dengan pola VK, tengah, dan akhir kata seperti pada [imbo] 'hutan', [tibo] 'sampai', dan [layi] 'lari', sedangkan alofon [I] hanya ditemukan pada posisi awal kata dengan pola V seperti pada [Ijaw] 'hijau'. Bunyi [i] dan [I] dikatakan berdistribusi komplementer karena kedua bunyi tersebut berada dalam ditribusi yang saling melengkapi.

Bunyi [o] dan [o] merupakan alofon dari fonem /o/. Berdasarkan transkripsi yang telah dilakukan, bunyi [o] ditemukan pada posisi tengah dan akhir kata seperti pada [loba] 'lebah' dan [Ino] 'dia', sedangkan bunyi [o] ditemukan pada posisi awal kata seperti pada [onam] 'enam'. Bunyi [o] dan [0] dikatakan berdistribusi komplementer karena kedua bunyi tersebut berada dalam distribusi yang saling melengkapi.

Tabel 6. Fonem Vokal IKKK

\begin{tabular}{|c|c|c|c|}
\hline & Depan & \multirow[b]{2}{*}{ Tengah } & Belakang \\
\hline & $\begin{array}{c}\text { Tak } \\
\text { Bulat }\end{array}$ & & Bulat \\
\hline Tertutup & $\mathrm{i}$ & & $\mathrm{u}$ \\
\hline $\begin{array}{l}\text { Setengah } \\
\text { Tertutup }\end{array}$ & e & & o \\
\hline terbuka & & $\mathrm{a}$ & \\
\hline
\end{tabular}

Berdasarkan uji pasangan minimal dan distribusi komplementer, dapat disimpulkan bahwa IKKK memiliki lima fonem vokal (Tabel 6). Semua fonem vokal IKKK dapat menempati berbagai posisi pada kata, yaitu pada posisi awal, tengah, dan akhir.

\section{Deskripsi dan Distribusi Konsonan}

Uji pasangan minimal yang dilakukan menghasilkan delapan belas buah fonem konsonan. Pasangan minimal konsonan yang ditemukan dalam IKKK dapat dilihat pada tabel berikut.

\section{Tabel 7. Pasangan Minimal Konsonan} IKKK

\begin{tabular}{|c|c|c|}
\hline $\begin{array}{c}\text { Fonem } \\
\text { Konsonan }\end{array}$ & $\begin{array}{c}\text { Pasangan } \\
\text { Minimal }\end{array}$ & Makna \\
\hline \multirow{2}{*}{$/ \mathrm{p} / / \mathrm{b} /$} & [punkan] & 'lempar' \\
\hline & [bunkan] & 'mati' \\
\hline \multirow{2}{*}{$/ \mathrm{t} / / \mathrm{d} /$} & [tuwo] & 'tua' \\
\hline & [duwo] & 'duwa' \\
\hline \multirow{2}{*}{$/ \mathrm{c} / / \mathrm{n} /$} & [kucian] & 'kucing' \\
\hline & [kunian] & 'kuning' \\
\hline \multirow{2}{*}{$/ \mathrm{j} / / \mathrm{m} /$} & [ljaw] & 'hijau' \\
\hline & [Imaw] & 'harimau' \\
\hline \multirow{2}{*}{$/ \mathrm{k} / / \mathrm{l} /$} & [kuwiy] & 'kurus' \\
\hline & [luwiy] & 'lurus' \\
\hline \multirow{2}{*}{$/ \mathrm{h} / / \mathrm{b} /$} & [ahat] & 'minggu' \\
\hline & [abat] & 'abad' \\
\hline \multirow{2}{*}{$/ \mathrm{g} / / \mathrm{b} /$} & [siga] & 'rantang' \\
\hline & [sіва] & 'merah' \\
\hline \multirow{2}{*}{$/ \mathrm{n} / / \mathrm{n} /$} & [nalow] & 'menyala' \\
\hline & [nalow] & 'ubi kayu' \\
\hline \multirow{2}{*}{$/ \mathrm{s} / / \mathrm{y} /$} & [pisaw] & 'pisau' \\
\hline & [piyaw] & 'piring' \\
\hline \multirow{2}{*}{ /w/ /y/ } & [jawi] & 'sapi' \\
\hline & [jayi] & 'jari' \\
\hline
\end{tabular}

Analisis data juga menunjukkan adanya konsonan yang distribusinya bersifat komplementer yang dapat dilihat pada tabel berikut.

\section{Tabel 8. Distribusi Komplementer} Konsonan IKKK

\begin{tabular}{|c|c|c|}
\hline Alofon & \multicolumn{2}{|c|}{ Distribusi Komplementer } \\
\hline \multirow{3}{*}[\mathrm{k}]{$[\mathrm{P}]$} & [kido]'kiri' & [elo?]'baik’ \\
\hline & [Iko] 'ini' & [ciye?]'satu’ \\
\hline & [buki?]'bukit' & [uьE?] 'urat' \\
\hline
\end{tabular}


Bunyi [k] dan [?] merupakan alofon dari fonem $/ \mathrm{k} /$. Bunyi [k] ditemukan pada posisi awal dan tengah kata seperti pada [kido] 'kiri' dan [Iko] 'ini', sedangkan bunyi [?] ditemukan pada posisi akhir kata seperti pada [elo?]'baik’. Bunyi [k] dan [?] dikatakan berdistribusi komplementer karena berada dalam distribusi yang saling melengkapi.

Tabel 9. Fonem Konsonan IKKK

\begin{tabular}{|c|c|c|c|c|c|c|c|c|c|c|}
\hline & \multicolumn{2}{|c|}{ 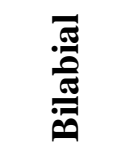 } & \multicolumn{2}{|c|}{$\frac{\vec{z}}{8}$} & \multicolumn{2}{|c|}{$\frac{\sqrt[\pi]{\pi}}{\sqrt[\pi]{\pi}}$} & \multicolumn{2}{|c|}{$\frac{\grave{J}}{\partial}$} & \multirow[t]{2}{*}{$\frac{\grave{\pi}}{\overrightarrow{3}}$} & \multirow[t]{2}{*}{ है } \\
\hline Hambat & $\mathrm{p}$ & $\mathrm{b}$ & $\mathrm{t}$ & $\mathrm{d}$ & $\mathrm{c}$ & $\mathrm{j}$ & $\mathrm{k}$ & $\mathrm{g}$ & & \\
\hline Nasal & & $\mathrm{m}$ & & $\mathrm{n}$ & & $\mathrm{n}$ & & $\eta$ & & \\
\hline Frikatif & & & $\mathrm{s}$ & & & & & & В & $\mathrm{h}$ \\
\hline Lateral & & & & 1 & & & & & & \\
\hline Semi Vokal & $\mathrm{w}$ & & & & $\mathrm{y}$ & & & & & \\
\hline
\end{tabular}

Uji pasangan minimal dan distribusi komplementer menghasilkan delapan belas fonem konsonan dalam IKKK (Tabel 9), yang dapat dibagi atas, delapan fonem hambat, empat fonem nasal, tiga fonem frikatif, satu fonem lateral, dan dua fonem semivokal.

Semua fonem konsonan IKKK dapat ditemukan pada posisi tengah kata, tetapi tidak semua dapat ditemukan pada posisi awal dan posisi akhir kata. Fonem konsonan yang tidak dapat ditemukan pada posisi awal kata ialah fonem konsonan glotal frikatif /h/. Adapun fonem konsonan yang tidak dapat menempati posisi akhir kata adalah fonem konsonan /b/, /d/, /c/, /j/, /k/, /g/, /n/, dan /s/.

\section{Deskripsi dan Distribusi Diftong}

Fonem diftong yang dimiliki IKKK juga ditentukan melalui uji pasangan minimal dan ditemukan sepuluh diftong seperti pada tabel beriku.
Tabel 10. Pasangan Minimal Diftong IKKK

\begin{tabular}{|c|c|c|}
\hline $\begin{array}{l}\text { Fonem } \\
\text { Diftong }\end{array}$ & $\begin{array}{c}\text { Pasangan } \\
\text { Minimal }\end{array}$ & Makna \\
\hline \multirow{2}{*}{ /iy//a/ } & [botiy] & 'betis' \\
\hline & [bota] & 'sembuh' \\
\hline \multirow{2}{*}{ /ay//uy/ } & [potay] & 'petai' \\
\hline & [potuy] & 'petir' \\
\hline \multirow{2}{*}{ /uw//o/ } & [ikuw] & 'ekor' \\
\hline & [iko] & 'ini' \\
\hline \multirow{2}{*}{ /aw//o/ } & [limaw] & 'jeruk' \\
\hline & {$[\lim \mathbf{o}]$} & 'lima' \\
\hline \multirow{3}{*}{ /ow/le/ } & [bonow] & 'benar' \\
\hline & [bone] & 'kutu \\
\hline & & (berbunyi)' \\
\hline \multirow{2}{*}{ /uə//ia/ } & [buluə] & 'buluh' \\
\hline & [bulia] & 'boleh' \\
\hline \multirow{2}{*}{ /uy//uo/ } & [lawuy?] & 'laut' \\
\hline & [lawuo?] & 'ikan' \\
\hline \multirow{2}{*}{ /ie//uy/ } & [putie] & 'putih' \\
\hline & [putuy] & 'putus' \\
\hline
\end{tabular}

Analisis data juga menunjukkan adanya diftong-diftong yang distribusinya bersifat komplementer seperti dalam tabel berikut. 


\begin{tabular}{|c|c|c|}
\hline Alofon & \multicolumn{2}{|c|}{ Distribusi Komplementer } \\
\hline$[\mathrm{ie}][\mathrm{i} \varepsilon]$ & $\begin{array}{l}\text { [putie] 'putih' } \\
\text { [kiyambie]'kelapa' }\end{array}$ & 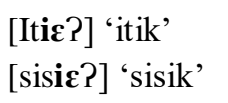 \\
\hline [uo][uo] & $\begin{array}{l}\text { [lawuo?] 'ikan' } \\
\text { [Iduoy] 'hidung' }\end{array}$ & $\begin{array}{l}\text { [yujus] 'gusi' } \\
\text { [tujus] 'tujuh' }\end{array}$ \\
\hline [ua][uə] & $\begin{array}{l}\text { [Isua?] 'besok' } \\
\text { [jaguay]'jagung' }\end{array}$ & $\begin{array}{l}\text { [jawuə] 'jauh' } \\
\text { [tukuə] 'pukul' }\end{array}$ \\
\hline
\end{tabular}

Bunyi [ie] dan [ic] merupakan alofon dari fonem diftong /ie/. Bunyi [ie] ditemukan pada posisi akhir kata seperti pada [putie] 'putih', sedangkan bunyi [ic] ditemukan pada posisi tengah kata seperti pada [Itie?] 'itik'. Bunyi [ie] dan [ie] dikatakan berdistribusi komplementer karena kedua bunyi tersebut berada dalam distribusi yang saling melengkapi.

Bunyi [uo] dan [uo] merupakan alofon dari fonem diftong /uo/. Bunyi [uo] ditemukan pada posisi tengah kata seperti pada [lawuo?] 'ikan', sedangkan bunyi [us] ditemukan pada posisi akhir kata seperti pada [yuyus] 'gusi'. Bunyi [uo] dan [u๊] dikatakan berdistribusi komplementer karena kedua bunyi tersebut berada dalam distribusi yang saling melengkapi.

Bunyi [ua] dan [uə] merupakan alofon dari fonem diftong /ua/. Bunyi [ua] ditemukan pada posisi tengah kata seperti pada [Isua?] 'besok', sedangkan bunyi [uə] ditemukan pada posisi akhir kata seperti pada [jawuə] 'jauh'. Bunyi [ua] dan [uə] dikatakan berdistribusi komplementer karena kedua bunyi tersebut berada dalam distribusi yang saling melengkapi.

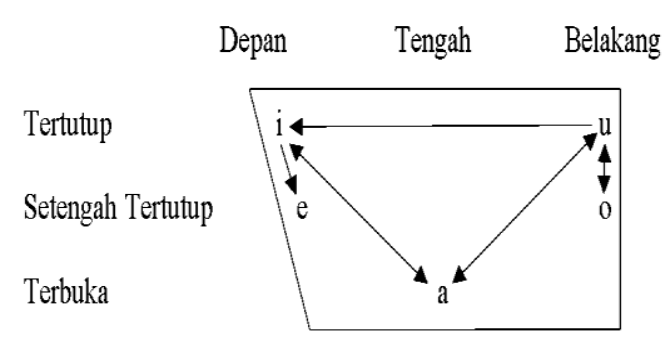

Gambar 12. Fonem Diftong IKKK

Berdasarkan uji pasangan minimal dan distribusi komplementer yang telah dilakukan, ditemukan sepuluh fonem diftong dalam IKKK (Tabel 12). Fonemfonem diftong tersebut adalah /ie/, /ia/, /iy/, /uo/, /ua/, /uy/, /uw/, /ay/, /aw/, dan /ow/. Distribusi fonem diftong IKKK dalam kata ditemukan pada posisi tengah dan akhir kata, sedangkan yang hanya ditemukan pada akhir kata adalah diftong /aw/, /ow/, /uw/, /ay/, dan /iy/.

\section{Pola Suku Kata}

Ditemukan delapan pola suku kata IKKK, yaitu pola $\mathrm{V}$ dalam [a.yi], VK dalam [ay], KV dalam [jo], KD dalam [pay], KVK dalam [de?], KKV dalam [ntu.wo], KDK dalam [I.duy?], dan KKVK dalam [nda?]. Semua kemungkinan variasi pola suku kata dapat dilihat pada Tabel 13 .

Meski dalam teori pola suku kata Clements dan Keyser (1983) hanya menjelaskan dua pola suku kata $\mathrm{K}$ (konsonan) dan $\mathrm{V}$ (vokal), penelitian IKKK ini menemukan pola suku kata dengan diftong seperti, KD dan KDK yang tidak ditemukan pada penelitian lainnya. Selain itu, pola suku kata yang ditemukan pada kata bersuku kata dua dan kata bersuku kata tiga dalam IKKK juga lebih beragam. 
Tabel 12. Deskripsi Pola Suku Kata IKKK

\begin{tabular}{|c|c|}
\hline & Pola Suku Kata \\
\hline \multirow{5}{*}{$\begin{array}{l}\text { Kata bersuku } \\
\text { kata satu }\end{array}$} & VK \\
\hline & KV \\
\hline & $\mathrm{KD}$ \\
\hline & KVK \\
\hline & KKVK \\
\hline \multirow{15}{*}{$\begin{array}{c}\text { Kata bersuku } \\
\text { kata dua }\end{array}$} & V.KV \\
\hline & V.KD \\
\hline & V.KVK \\
\hline & V.KDK \\
\hline & VK.KV \\
\hline & VK.KD \\
\hline & VK.KVK \\
\hline & VK.KDK \\
\hline & KV.KV \\
\hline & KV.KVK \\
\hline & KV.KKVK \\
\hline & KVK.KV \\
\hline & KVK.KVK \\
\hline & KKV.KVK \\
\hline & KKV.KV \\
\hline \multirow{12}{*}{$\begin{array}{l}\text { Kata bersuku } \\
\text { kata tiga }\end{array}$} & KV.V.KVK \\
\hline & KV.KV.KV \\
\hline & KV.KV.KVK \\
\hline & KV.KVK.KV \\
\hline & KV.KVK.KVK \\
\hline & KV.KV.KDK \\
\hline & KV.KVK.KKVK \\
\hline & KVK.KV.KV \\
\hline & KVK.KV.KVK \\
\hline & KVK.KV.KDK \\
\hline & KV.KVK.KD \\
\hline & KV.KVK.VK \\
\hline Kata bersuku & KV.KV.KV.KV \\
\hline kata empat & KV.KV.KV.KVK \\
\hline
\end{tabular}

\section{SIMPULAN}

Analisis

sistem

fonem

memperlihatkan bahwa IKKK memiliki 33 fonem, yaitu 5 fonem vokal, 18 fonem konsonan, dan 10 fonem diftong. Berdasarkan analisis yang dilakukan, terdapat 8 pola suku kata IKKK yang terdiri atas $\mathrm{V}, \mathrm{VK}, \mathrm{KV}, \mathrm{KD}, \mathrm{KVK}, \mathrm{KKV}$, KDK, dan KKVK.

Bunyi, fonem, distribusi fonem, dan pola suku kata yang ditemukan pada penelitian ini menunjukkan bahwa isolek
Kuntu memiliki sistem fonem yang berbeda dengan bahasa lainnya. Keberagaman diftong yang ditemukan pada penelitian ini jika dibandingkan dengan penelitian dialek bahasa Minangkabau terdahulu yang memiliki banyak kesamaan juga membuktikan bahwa isolek Kuntu termasuk dalam dialek bahasa Minangkabau.

\section{DAFTAR PUSTAKA}

Arman, D. 2014, Juni 8. Kuntu Darussalam: Kerajaan Islam Pertama di Riau. Retrieved Februari 2, 2021, from https://kebudayaan.kemdikbud.go.id I: https://kebudayaan.kemdikbud.go.id /bpnbkepri/kuntu-darussalamkerajaan-islam-pertama-diriau/\#: :text=Desa\%20Kuntu\%20ter masuk\%20desa\%20tertua,mengemb angkan\%20agama\%20Budha\%20di $\% 20$ Kuntu.

Clements, G., \& Keyser, S. 1983. CV Fonologi: Teori Generatif Suku Kata (Linguistic Inquiry Monograph 9). Cambridge: MIT Press.

Ermawati, \& Hermaliza. 2019. Nomina Bahasa Melayu Riau Dialek Kampar: Tinjauan Bentuk Morfologis. GERAM (Gerakan Aktif Menulis), 116 Volume 7, Nomor 2,.

Faizah AR, H. 2012. Kategori Fatis dalam Bahasa Melayu Riau Dialek Kuok. Litera, 60-71, Vol. 11 No.1.

Hamidy, U. 1994. Bahasa Melayu dan Kreativitas Sastra di Riau. Pekanbaru: UNRI Press.

Katamba, F. 1989. An Introduction to Phonology (Learning About Language). Londong and New York: Longman.

Kemendikbud. (n.d.). https://petabahasa.kemdikbud.go.id/ - Retrieved Juli 18, 2021, from https://kemdikbud.go.id/: 
https://petabahasa.kemdikbud.go.id/ provinsi.php?idp=Riau\#20

Krulikowska, Ż., Nadra, \& Yusdi, M. 2020. Sistem Fonologi Bahasa Melayu Jambi Isolek Sarolangung. Arbitrer, 173-181 Vol.7 No.2.

Martius. 2012. Studi Gejala Fonemis Antara Bahasa Melayu Riau Dialek Kampar dan Bahasa Indonesia. Jurnal Sosial Budaya, 244-260, Vol.9 No.2.

McMahon, A. M. 2001. An Introduction to English Phonology. Edinburg: Edinburg University Press.

Nadra. 2003. The Dialect of Minangkabau Language in Riau Province. Kajian Sastra, 176-181 Nomor 3.

Nadra, \& Reniwati. 2009. Dialektologi: Teori dan Metode. Yogyakarta: Elmatera Publishing.

Pike, K. 1966. Phonemics: A Technique for Reducing Languages to Writing. Ann Arbor: The University of Michigan Press.
Republik Indonesia. 1958. UndangUndang Republik Indonesia Nomor 61 Tahun 1958 tentang Penetapan "Undang-Undang Darurat No.19 Tahun 1957 tentang Pembentukan Daerah-Daerah Swatantra Tingkat I Sumatera Barat, Jambi dan Riau" Sebagai Undang-Undang. Jakarta: DPR RI.

Sudaryanto. 1988. Metode Linguistik: Bagian Kedua Metode dan Aneka Teknik Pengumpulan Data. Yogyakarta: Universitas Gadjah Mada.

Sudaryanto. 2015. Metode dan Aneka Teknik Analisis Bahasa: Pengantar Penelitian Wahana Kebudayaan Secara Linguistis. Yogyakarta: Sanata Dharma University Press.

Sumarsono, Lindyastuti, \& Widyanto, S. 1997. Sistem Pemerintahan Tradisional di Riau. Jakarta: Departemen Pendidikan dan Kebudayaan RI. 